\title{
Factor XIIIA subunit and Crohn's disease
}

\author{
M Hudson, A J Wakefield, R A Hutton, E A Sankey, A P Dhillon, L More, R Sim, R E Pounder
}

\begin{abstract}
Factor XIIIA is the active subunit of plasma factor XIII that is responsible for cross linking fibrin into a stable clot. Sixteen patients with Crohn's disease were studied prospectively from relapse (Crohn's disease activity index $>150$ ) into remission. Plasma factor XIIIA concentrations were significantly lower in active disease (median 63 (95\% CI 46-72) U/dl) than remission (median $90(95 \%$ CI 60-112) $\mathrm{U} / \mathrm{dl} ; \mathrm{p}=\mathbf{0 . 0 0 2}$ ). Plasma factor XIIIA concentrations correlated positively with the activity index $(p=0.005)$ and platelet count $(p=0.003)$, and negatively with serum albumin $(p=0.006)$. In five patients with persistent aggressive disease, the factor XIIIA concentration remained below the lower range of normal despite apparent clinical improvement in response to medical treatment. Tissues from three patients who underwent surgical resection during the study were immunostained for factor XIIIA. Gut mucosal and submucosal macrophages stained strongly for factor XIIIA. In one patient, capillary thrombi near superficial mucosal erosions immunostained for factor XIIIA in macroscopically normal mucosa. Similar changes were identified in more severely inflamed sections of intestine from the other two patients. The demonstration of significantly low plasma factor XIIIA concentrations in active Crohn's disease, and the immunostaining of factor XIIIA in capillary thrombi in the bowel wall, suggest that activation of coagulation may be involved in the pathogenesis of Crohn's disease. The plasma factor XIIIA concentration may prove a useful laboratory marker of disease activity.

(Gut 1993; 34: 75-79)
\end{abstract}

Inflammatory Bowel Disease Study Group University Departments of Medicine $M$ Hudson

A J Wakefield

R E Pounder

and Histopathology

E A Sankey

A P Dhillon

L More

R Sim

and Haemophilia Centre and Haemostasis Unit R A Hutton

Royal Free Hospital and School of Medicine, London

Correspondence to: Prof R E Pounder, University Department of Medicine, Royal Free Hospital School of Medicine, Rowland Hill Street, London NW3 2QG

Accepted for publication 19 June 1992
We have described multifocal obliteration of the intestinal microvasculature in Crohn's disease.' Thromboses occur in association with granulomatous or lymphocytic inflammation of the affected blood vessels. ${ }^{2}$ In addition, recent studies have shown serological evidence of persistent thrombogenesis in clinically active and quiescent Crohn's disease, as judged by established scores of clinical disease activity (Crohn's disease activity index (CDAI) and HarveyBradshaw score). ${ }^{3-5}$ These clinical scores rely heavily on the patient's symptoms, ${ }^{6}$ and they fail to reflect the ongoing pathogenic processes of Crohn's disease. This failure is highlighted by recent postsurgical endoscopic studies, which have shown that active mucosal inflammation and ulceration may be present in patients with symptomatically quiescent disease. ${ }^{7}$

Estimation of the C-reactive protein, as a serological marker of inflammation, measures a response that is several steps removed from the disease process in the intestine. C-reactive pro- tein is a cytokine induced liver derived acute phase protein. ${ }^{6}$ As such, it may be influenced by a number of variables, including corticosteroid therapy, that are not directly related to changes in Crohn's disease activity.

A direct index of activity is required for the clinical evaluation of Crohn's disease, that reflects the ongoing pathogenic processes taking place in the intestine. Factor XIII is the final component of the clotting cascade. ${ }^{9}$ It circulates in plasma as a tetrameric molecule of two identical A (proenzyme) and two identical S (carrier protein) subunits. The generation of thrombin causes the factor XIII molecule to change configuration into an activated form XIII $(2 \mathrm{~A}, 2 \mathrm{~S})$ which, in the presence of fibrin and calcium, releases the activated factor XIIIA. Factor XIIIA is responsible for the cross linking of fibrin into stable adherent clot. ${ }^{9-10}$ Consumption of XIIIA in foci of thrombisis is reflected in a fall of the factor's plasma concentration.

Based upon the morphological and serological evidence for thrombosis in histologically active Crohn's disease, we have measured and compared factor XIIIA concentration with measures of clinical disease activity in a prospective study of patients with Crohn's disease.

\section{Methods}

\section{PATIENTS}

Sixteen patients with endoscopic, histological or radiological evidence of Crohn's disease were studied prospectively from relapse $(\mathrm{CDAI}>150)$ into remission (CDAI <150). Their median age was 35 (range 17-74) years, and they received conventional medical and surgical treatment (Table I). At each hospital visit, the clinical details necessary to calculate the CDAI were recorded and blood samples were obtained for routine tests and factor XIII assay. After venepuncture, $9 \mathrm{ml}$ blood were added to $1.0 \mathrm{ml} 0 \cdot 109$ $M$ trisodium citrate and centrifuged at $2000 \mathrm{xg}$ for 15 mintues at $4^{\circ} \mathrm{C}$. The resulting plasma was centrifuged as before and the supernatant was stored at $-40^{\circ} \mathrm{C}$ until assayed. The factor XIIIA and $S$ subunits were measured by the Laurell rocket electroimmunoassay," using monospecific antisera (Behring Diagnostics, Hounslow, UK). Results were expressed as a per cent of a pooled plasma standard from 20 healthy subjects.

Fibrinopeptide-A (Boehringer-Mannheim, Lewes, UK) and d-dimer (Porton, Newmarket, UK) were measured by enzyme linked immunoadsorbent assay (ELISA) as markers of fibrinogen cleavage and firinolysis respectively. ${ }^{3}$

Three patients underwent surgery during the course of the study. Immediately after resection, the specimens underwent arterial cannulation, heparin saline flush and perfusion fixation with 


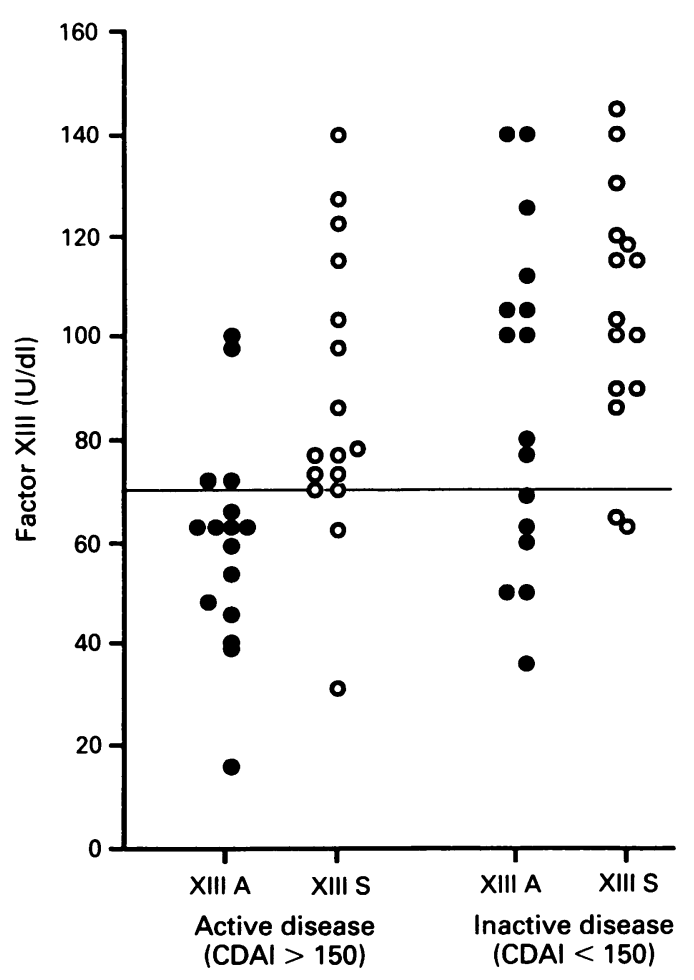

Figure 1: Fourteen of 16 patients have plasma XIIIA concentrations at or below the lower range of normal in active disease but in remission 10/16 patients have a plasma XIIIA concentrations within the normal range.

$10 \%$ formal saline at a pressure of $100 \mathrm{~cm} \mathrm{H}_{2} \mathrm{O} .{ }^{12}$ From paraffin processed blocks, $4 \mu \mathrm{m}$ sections were cut and stained with haematoxylin and eosin. Sections showing areas of either microscopically non-inflamed non-ulcerated bowel, and other areas with inflammation, were selected and immunostained with monoclonal platelet glycoprotein IIIa (1:5 dilution, DAKO Ltd, High Wycombe, UK) and polyclonal factor XIIIA (1:400 dilution, Behring Diagnostics). Standard immunohistochemical and development techniques (peroxidase antiperoxidase, avidin biotin complex, diaminobenzidine and alkaline phosphatase) were used.

\section{STATISTICAL ANALYSIS}

Statistical analyses were performed using the Oxstat program (Wallingford Computing Services, Wallingford, Oxfordshire, UK).

The study was approved by the Ethics Committee of Hampstead Health Authority; all patients provided written, informed consent before entering the study.

\section{Results}

The plasma concentration of factor XIIIA was significantly lower in relapse (median 63 (95\% CI 46-72) $\mathrm{U} / \mathrm{dl}$ ) than when the 16 patients first went into clinical remission (median $90(95 \%$ CI 60 112) U/dl), $p=0 \cdot 002$, Wilcoxon's rank-sum test (Fig 1). The plasma XIII S concentration was also significantly lower in relapse compared with remission (median 78 (95\% CI 73-115) and 109 (95\% CI 90-118) U/dl, respectively; $\mathrm{p}=0.005$ ). In relapse the ratio of the mean between XIIIA and $S$ concentrations was $1: 1 \cdot 5$, whereas it was $1: 1 \cdot 2$ when in remission.
Activation of coagulation was confirmed at presentation in these patients by raised fibrinopeptide-A and d-dimer concentrations (normal range $<3 \mathrm{ng} / \mathrm{ml}$ and $<300 \mathrm{ng} / \mathrm{ml}$ respectively). The fibrinopeptide-A's were higher (median $5(95 \%$ CI 3-12) $\mathrm{ng} / \mathrm{ml}$ ) at presentation with active disease compared with remission (median $2(95 \%$ CI $0 \cdot 8-2 \cdot 8) \mathrm{ng} / \mathrm{ml}) .{ }^{3}$ The difference did not reach statistical significance; $\mathrm{p}=0 \cdot 141$, Wilcoxon's rank-sum test. There was no significant correlation between fibropeptide$A$ and factor XIIIA (Spearman rank correlation, $p=0.9$ ). The lack of correlation can be explained by the different half lives of the two parameters, in the case of factor XIIIA it is between 10 and 14 days whereas fibrinopeptide- $A$ is only minutes. The d-dimers were higher at presentation with active disease (median 305 (95\% CI 16-625) ng/ $\mathrm{ml}$ ) than when in remission (median $49(95 \% \mathrm{CI}$ $12-400) \mathrm{ng} / \mathrm{ml}$ ) confirming modest reactive fibrinolysis.

Two of the patients had factor XIIIA concentrations within the normal range at presentation with a relapse, but both had an infective complication of their Crohn's disease; one a perineal abscess and the other a peristomal abscess. Neither patient had any evidence of active 'inflammatory' Crohn's disease after resolution of infection. Clinical improvement was associated in nine of the 16 patients with a rise of factor XIIIA concentration into the normal range (Fig 2). Five patients, however, had persistently low factor XIIIA concentrations despite medical treatment and an improvement of their symptoms, as assessed by the CDAI. One of these patients required surgery during the course of the study, and one has subsequently undergone surgery. The remaining three patients had persistent, active disease despite continued immunosuppressive treatment for 18 months of follow up

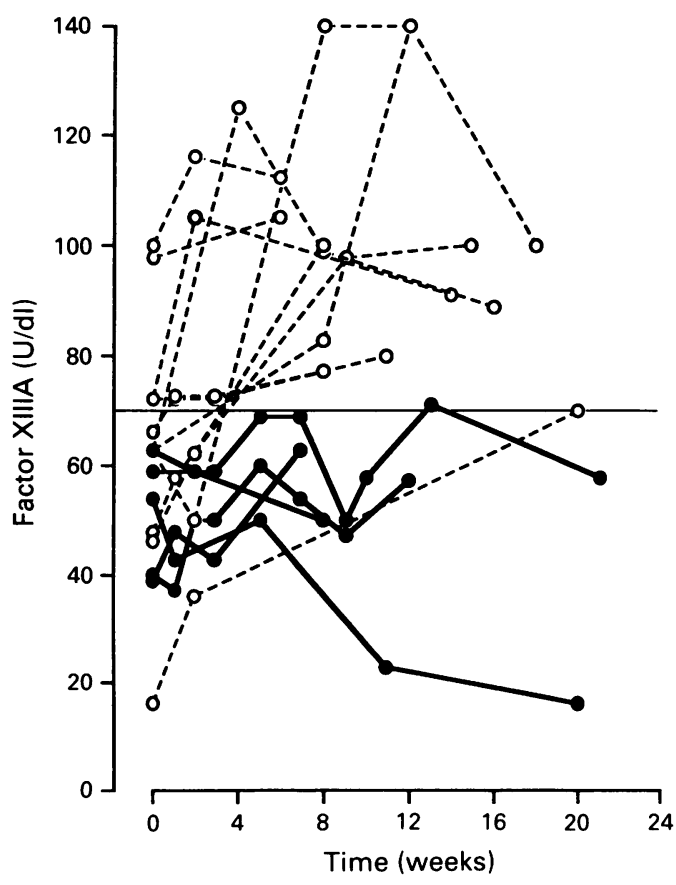

Figure 2: Solid black lines and dots represent the five of 16 patients who have a persistent plasma XIIIA concentration below the lower range of normal despite apparent symptomatic improvement on treatment. 
Clinical data and treatment received in 16 patients with Crohn's disease during the study

\begin{tabular}{|c|c|c|c|c|c|c|c|c|}
\hline Patients & $\begin{array}{l}\text { Age } \\
(y r)\end{array}$ & Sex & $\begin{array}{l}\text { Duration } \\
\text { of disease }\end{array}$ & $\begin{array}{l}\text { Site of } \\
\text { disease }\end{array}$ & Smoke & $\begin{array}{l}\text { Treatment } \\
\text { received }\end{array}$ & $\begin{array}{l}\text { Extra-intestinal } \\
\text { features }\end{array}$ & $\begin{array}{l}\text { CDAI at } \\
\text { presentation }\end{array}$ \\
\hline $1^{\star}$ & 17 & F & 4 years & Small/large bowel & 0 & P/AZA/MEZ & - & 287 \\
\hline $2+$ & 25 & $\mathrm{~F}$ & 7 years & Ileo-colonic & 0 & P/AZA/SSZ & Arthritis/mouth & 332 \\
\hline $3^{\star}$ & 27 & $M$ & 8 years & Recurrence in & 0 & $\mathrm{P} / \mathrm{AZA} / \mathrm{MEZ}$ & Mouth ulceration & 300 \\
\hline 4 & 32 & $\mathrm{~F}$ & 3 years & $\begin{array}{l}\text { lleositomy } \\
\text { Proctosigmoiditis }\end{array}$ & $20 /$ day & P/AZA/SSZ & Arthritis & 410 \\
\hline 5 & 48 & $M$ & 18 years & $\begin{array}{l}\text { Colonic erythema } \\
\text { nodosum }\end{array}$ & 0 & P/AZA/MEZ & Arthritis & 294 \\
\hline $6^{\star}$ & 37 & F & 6 years & Colonic & 0 & P/MEZ surgery & - & 357 \\
\hline 7 & 74 & $M$ & 2 months & Proctosigmoiditis & 0 & P/SSZ/Warfarin & $\begin{array}{l}\text { Deep venous } \\
\text { thrombosis at week } 3\end{array}$ & 206 \\
\hline${ }_{9}^{8+}$ & 67 & $M$ & 4 months & Ileo-caecal & 0 & P/Surgery & - & 279 \\
\hline $\begin{array}{r}9 \\
10\end{array}$ & 32 & $\mathrm{~F}$ & $\begin{array}{l}14 \text { years } \\
18 \text { months }\end{array}$ & Proctosigmoiditis & 0 & P/SSZ & 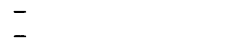 & $\begin{array}{l}245 \\
391\end{array}$ \\
\hline 11 & 70 & $\stackrel{M}{M}$ & $\begin{array}{l}18 \text { montns } \\
2 \text { months }\end{array}$ & $\begin{array}{l}\text { Ileo-caecal } \\
\text { Colonic }\end{array}$ & $40 /$ day & P/MEZ & $\begin{array}{l}- \\
-\end{array}$ & 300 \\
\hline $12^{\star}$ & 17 & $M$ & 3 years & Ileo-caecal & 0 & P/MEZ & - & 160 \\
\hline & 65 & M & 4 weeks & Small/arge bowel & 0 & P/MEZ! & - & 280 \\
\hline 14 & 67 & $\mathbf{M}$ & 15 years & Perineal abscess & 0 & P/AZA/MEZ & & 160 \\
\hline 15 & 39 & $\mathbf{F}$ & 15 years & Ileostomy stroma & $5 /$ day & & Sacro ileitis & 238 \\
\hline $16^{\star}$ & 22 & $\mathbf{F}$ & 1 year & Small/large & $2 /$ day & P/AZA/SSZ & Mouth ulcers & 200 \\
\hline
\end{tabular}

The five patients with persistently low factor XIIIA concentrations are denoted with ' $\star$ ' and the two patients whose factor XIIIA concentrations rose only after surgery with ' + '. $P=$ prednisolone; $M E Z=$ mesalazine; $A Z A=$ azathioprine; $S S Z=$ sulphasalazine.

(Table). Two of the nine patients who improved, both in terms of CDAI and a sustained rise of factor XIIIA concentrations, did so only after surgery. None of the remaining seven patients have required surgical intervention during 18 months of follow up.

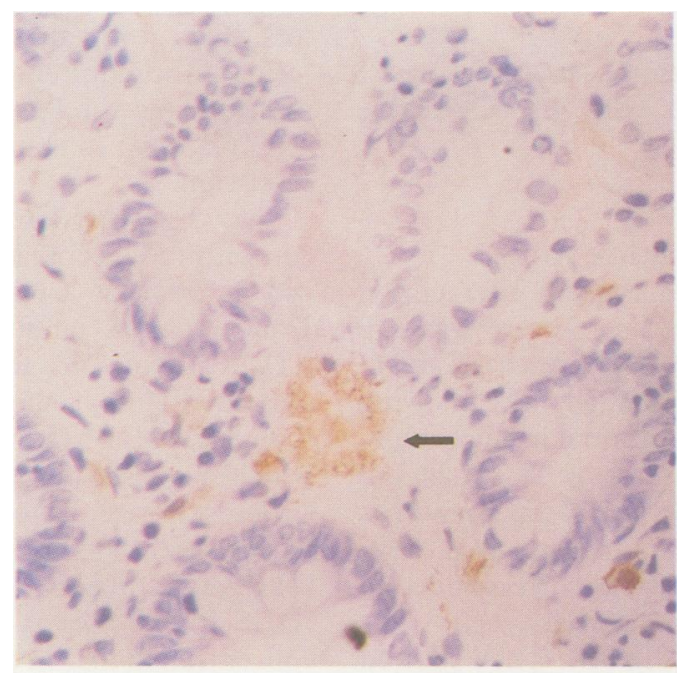

Fig $3 A$

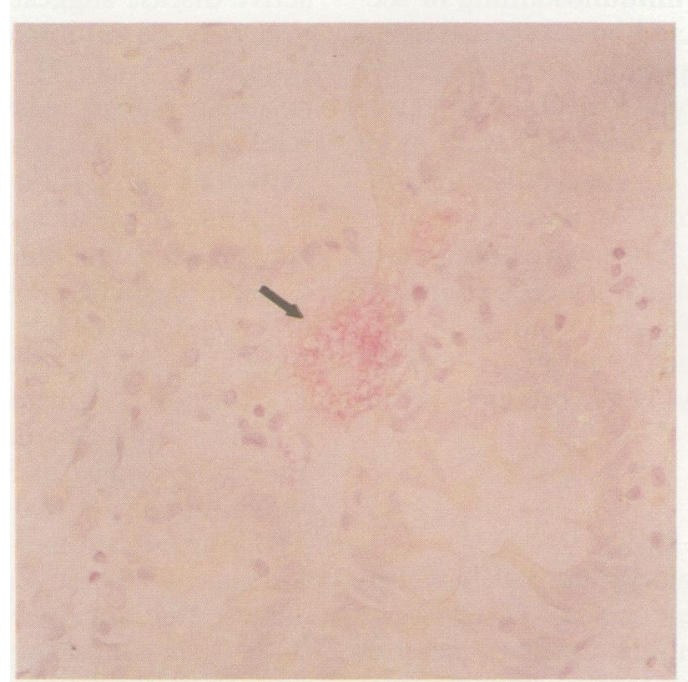

Factor XIIIA assayed in 61 plasma samples has a significant negative correlation with the CDAI $(p=0.005)$ and platelet count $(p=0.003$; Spearman rank correlation test). There is a significant positive correlation between the factor XIIIA concentration and the serum albumin level,

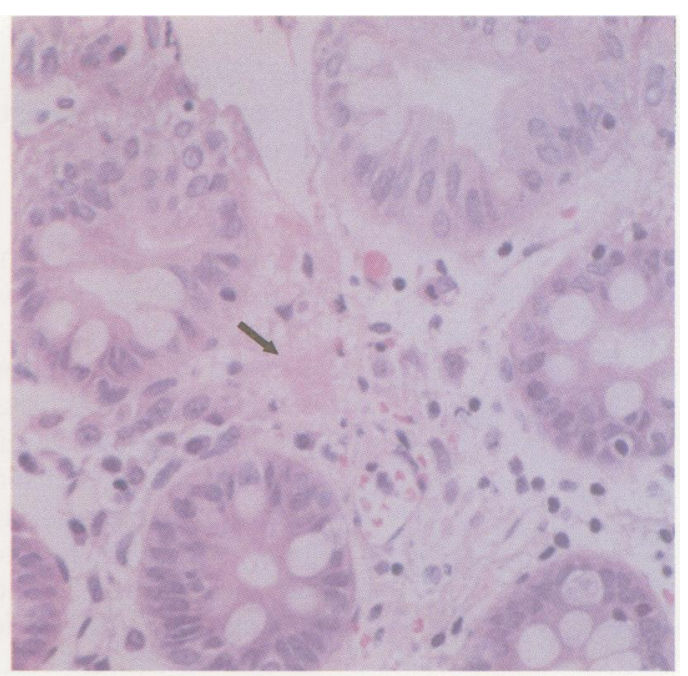

Fig $3 B$

Figure 3(A): A plug of material within the superficial lamina propria showing immunostaining for factor XIIIA (arrow) (B) Plug of eosinophilic material (arrow) close to damaged mucosal capillary with extravasated red blood cells.

(C) Superficial mucosal plug at tip of ruptured capillary immunostaining with platelet glycoprotein III a (arrow). 


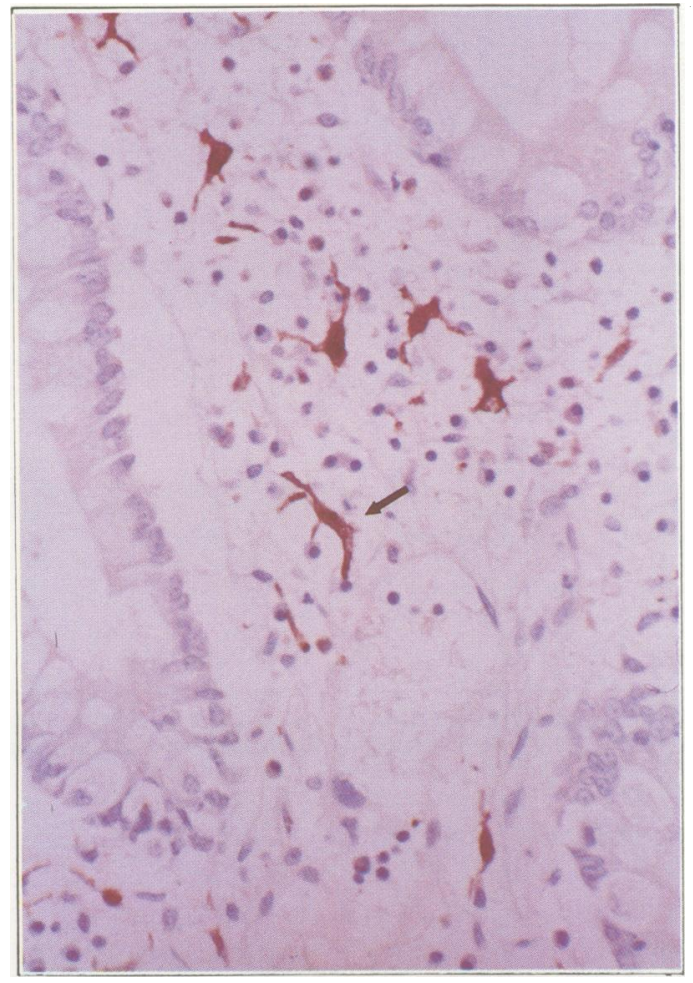

Figure 4: Factor XIIIA positive cells within the lamina propria apparently making dentritic contacts with lymphocytes and plasma cells (arrow).

$\mathrm{p}=0.006$ (Spearman rank correlation test). There is no correlation with the C-reactive protein $(\mathrm{p}=0 \cdot 319)$.

\section{TISSUE LOCALISATION OF FACTOR XIIIA}

Three patients underwent surgical intervention during the study. In areas of severe mucosal ulceration, in two of these cases (patients 2 and 6) and in the third case from an area showing epithelial erosion, lamina proprial haemorrhage, but no inflammation (patient 8), material immunostaining for factor XIIIA was present as plugs within or close to ruptured mucosal capillaries (Figure 3A). These plugs corresponded to eosinophilic 'fibrinoid' material seen after haematoxylin and eosin (Fig 3B). They showed immunostaining for platelet glycoprotein IIIa (Fig 3C). Factor XIIIA immunostaining of sections from all three resected bowel specimens in this study identified a population of dendritic cells scattered singly throughout the connective tissue of the bowel wall. These cells were more numerous in areas of chronic inflammation. Factor XIIIA positive cells occupied the lower mucosa and submucosa. They were observed in contact with other inflammatory cells (lymphocytes and plasma cells; Figure 4) and mast cells. They were often prominent around vessels of the submucosa, where they were present in the tunica adventitia.

\section{Discussion}

In a study of macroscopically normal bowel in Crohn's disease, Sankey et $a l^{12}$ noted loose accumulations of eosinophilic, fibrillary material in the superficial lamina propria. This material formed 'fibrinoid' plugs partly occluding the lumen of damaged capillaries, particularly at the point of rupture. Immunohistochemical localisation of factor XIIIA to 'fibrinoid' capillary plugs in the mucosa provides histological evidence of factor XIIIA consumption that might explain the low plasma concentrations of this factor in active Crohn's disease.

The finding of perivascular factor XIIIA positive dendritic macrophages in the submucosa in Crohn's disease is a new finding. Similar cells have been described in benign fibrotic skin lesions and pulmonary fibrosis ${ }^{13-17}$ and shown to be of monocyte/macrophage lineage (RFD7 and leu-M3 positive cells). The association of these cells with fibrotic diseases may be of importance. In addition to its haemostatic properties, factor XIIIA is a potent stimulus to fibroblast proliferation. ${ }^{10}$ It is possible that these cells participate in the submucosal fibrosis that is a characteristic feature of Crohn's disease.

Coagulation is active in the intestine of Crohn's disease (as confirmed in the systemic circulation by the raised fibrinopeptide- $A$ and d-dimer concentrations), and the present data suggest that XIIIA may provide an additional indication of disease status to the CDAI and C-reactive protein. Patients with chronic persistent disease had concentrations of XIIIA that remained below the lower limit of normal, despite improvements in their symptoms and other inflammatory parameters. This group also had the worst outcome in terms of the requirement for surgical resection of diseased bowel and the need for immunosuppressive treatment to maintain symptomatic clinical remission.

The disproportionate fall in plasma XIIIA concentration compared with XIIIS, suggests consumption as a result of active coagulation. Under normal circumstances the XIIIA and XIIIS subunits are found in a 1:1 ratio in the plasma, Figure 1 shows that XIIIA falls more than XIIIS (1:1.5 ratio) in active Crohn's disease, which suggests that, during periods of active Crohn's disease, factor XIII has undergone proteolysis and that XIIIA has been utilised in the coagulative process, leaving the carrier protein XIIIS in the plasma albeit at a slightly lower concentration than in control subjects. The fall of both factor XIIIA and XIIIS concentration in active disease suggests that factor XIII production may be inhibited during the acute phase response. There is no correlation, however, between plasma concentrations of XIIIA or XIIIS and C-reactive protein. In areas of inflammation factor XIII may be cleaved by neutrophil elastases, and decreased survival of the subunits may further contribute to its loss from plasma. ${ }^{1018}$

Total plasma factor XIII concentrations have been reported to fall in active Crohn's disease, correlating significantly with serum albumin. ${ }^{19}$ The authors suggested the factor XIII may be lost through a leaky mucosa, but factor XIII has a molecular weight of 320000 daltons compared with albumin's 69000 daltons. The lowest factor XIII concentrations were found in two patients with haemorrhagic Crohn's colitis; the authors suggest that the bleeding was because of low factor XIII concentrations and fragile clot. This suggestion conflicts with in vitro studies which show that only $10 \%$ or less of the factor XIIIA 
found in plasma is required for normal haemostasis. ${ }^{20}$ Studies from Japan and Poland have shown low concentratons of factor XIIIA in active ulcerative colitis, ${ }^{21}{ }^{22}$ with apparent clinical and endoscopic improvement in one patient after treatment with recombinant factor XIIIA. ${ }^{22}$ Similar falls in factor XIIIA have been noted in Henoch Schonlein purpura, a vasculitic syndrome characterised by fibrin deposition, ${ }^{23}$ involving skin, joints, kidneys, and the gastrointestinal tract. In addition to reflecting increased consumption - for example, in wound healing or disseminated intravascular coagulation $^{10}$ - a low plasma factor XIIIA concentration may indicate decreased XIIIA synthesis as a result of chronic liver disease. None of the patients in this study had concurrent liver disease but fibrinopeptide- $A$ and d-dimer concentrations were raised in the active phase of disease.

In conclusion, this study has identified both a deficiency of factor XIIIA subunit in the plasma of patients with active Crohn's disease, and deposition of XIIIA in diseased intestinal tissues. Initial observations suggest that XIIIA may provide an additional marker of disease activity to the currently available clinical disease activity scores and the $\mathrm{C}$-reactive protein.

The authors are indebted to the National Association for Colitis and Crohn's disease ( $M$ Hudson is the Leslie Parrot Research Fellow), the Wellcome Trust (A J Wakefield is supported by the Wellcome Trust), Crohn's in Childhood Research Appeal, and the Lander family. We would also like to thank the staff of the Haemostasis Unit for their expert technical assistance and Ms Doris Elliott for her help in preparing the manuscript.

1 Wakefield AJ, Sawyerr AM, Dhillon AP, Pittilo RM, Rowles PM, Lewis AAM, et al. Pathogenesis of Crohn's disease: multifocal gastrointestinal infarction. Lancet 1989; i: $1057-62$.

2 Wakefield AJ, Sankey EA, Dhillon AP, Sawyerr AM, More L, Sim R, et al. Granulomatous vasculitis in Crohn's disease. Gastroenterology 1991; 100: 1279-87.

3 Hudson M, Hutton RA, Wakefield AJ, Sawyerr AM, Kernoff Hudson M, Hutton RA, Wakefield AJ, Sawyerr AM, Kernoff PBA, Pounder RE. Evidence for accelerated throm-
bogenesis in Crohn's disease. Gastroenterology 1991; 100: A217.
4 Best WR, Becktel JM, Singleton JW, Kern F Jr. Development of a Crohn's disease activity index. Gastroenterology 1976; 70: 439-44.

5 Harvey RF, Bradshaw JM. A simple index of Crohn's disease activity. Lancet 1980; i: 514.

6 Hodgson HJF, Mazlam MZ. Assessment of drug therapy in inflammatory bowel disease. Aliment Pharmacol Ther 1991; 5: $555-84$

7 Modigliani R, Mary JY, Simon JF, Cortot A, Soule JC, Gendre JP, et al. Clinical, biological and endoscopic picture of attacks of Crohn's disease. Gastroenterology 1990; 98: $811-8$.

8 Whicher JT, Evans SW. Acute phase proteins. Hospital Update 1990; 16: 899-905.

9 Curtis CG. Plasma factor XIII. In: Arthur L Bloom, Duncan P Thomas, eds. Haemostasis and thrombosis. 2nd ed. Edinburgh: Churchill Livingstone, 1987: 216-22.

10 McDonagh J. Structure and function of factor XIII. In: Colman RW, Hirsh J, Marder VJ, Salzman EW, eds. Haemostasis and thrombosis. Basic principles and clinical practice. 2nd ed. Philadelphia: J B Lippincott, 1987: 289300.

11 Laurell CB. Quantitative investigation of proteins by electrophoresis in agarose gel containing antibodies. Annal Biochem 1966; 15: 45-52.

12 Sankey EA, More L, Dhillon AP, Wakefield AJ, Sim R, Sawyerr AM, et al. Microvascular injury associated with superficial mucosal lesions in Crohn's disease. Gastroenterology 1991; 100: A612.

13 Nemes Z, Thomazy V. Factor XIIIa and the classic histiocytic markers in malignant fibrous histiocytoma: a comparative markers in malignant fibrous histiocytoma: a comparative

14 Fletcher CDM. Benign fibrous histiocytoma of subcutaneous and deep soft tissue: A clinicopathologic analysis of 21 cases. Am f Surg Pathol 1990; 14: 801-9.

15 Reid MB, Gray C, Fear JD, Bird CC. Immunohistological demonstration of factors XIIIa and XIIIs in reactive and neoplastic fibroblastic and fibro-histiocytic lesions. Histopathology 1986; 10: 1171-8.

16 Adany R, Glukhova MH, Kabakov AY, Muszbek L. Characterisation of connective tissue cells containing factor XIII subunit a. F Clin Pathol 1988; 41: 49-56.

17 Toida $M$, Okumura Y, Takami T. Cells containing factor XIIIa and pulmonary fibrosis induced by bleomycin. f Clin Pathol 1991; 44: 255-6.

18 Machovich R, Owen WG. The elastase-mediated pathway of fibrinolysis. Blood Coagulation and Fibrinolysis 1990; 1 : fibrinolysis. Blood Coagulation and Fibrinolysis 1990; 1:

9 Wisen O, Gardlund B. Haemostasis in Crohn's disease: low factor XIII levels in active disease. Scand $\mathcal{F}$ Gastroenterol 1988; 23: 961-6.

20 Duckert F. Documentation of the plasma factor XIII deficiency in man. Ann NY Acad Sci 1972; 202: 190-9.

21 Standnicki A, Kloczko J, Nowak A, Sierka E, Sliwinski Z. Factor XII subunits in relation to some other haemostatic parameters in ulcerative colitis. Am 7 Gastroenterol 1991; 86: 690-3.

22 Suzuki R, Toda H, Takamura Y. Dynamics of blood coagulation factor XIII in ulcerative colitis and preliminary study of the factor XIII concentrate. Blut 1989;59: 162-4.

23 Hendriksson P, Hedner U, Nilson IM. Factor XIII (fibrin stabilising factor) in Henoch-Schonlein purpura. Acta Paediatr Scand 1977; 66: 273-7. 